\title{
PHENOTYPIC PLASTICITY AND HETEROCHRONY IN CICHLASOMA MANAGUENSE (PISCES, CICHLIDAE) AND THEIR IMPLICATIONS FOR SPECIATION IN CICHLID FISHES
}

\author{
AXEL Meyer \\ Museum of Vertebrate Zoology and Department of Zoology, \\ University of California, Berkeley, CA 94720
}

\begin{abstract}
Cichlid fishes in African rift lakes have undergone rapid speciation, resulting in "species flocks" with more than 300 endemic species in some of the lakes. Most researchers assume that there is little phenotypic variation in cichlid fishes. I report here extensive phenotypic plasticity in a Neotropical cichlid species. I examined the influence of diet on trophic morphology during ontogeny in Cichlasoma managuense. Two groups of full siblings were fed two different diets for eight months after the onset of feeding; thereafter both groups were fed a common diet. Phenotypes that differed significantly at 8.5 months converged almost completely at 16.5 months. If feeding on two different diets is continued after 8.5 months, the phenotypes remain distinct. Differences in diet and possibly in feeding mode are believed to have caused these phenotypic changes. Phenotypic plasticity is described in terms of a qualitative model of heterochrony in which phenotypic change in morphology is explained as retardation of the normal developmental rate. If phenotypic expression of morphology is equally plastic in African cichlid species as it may be in the American cichlids, as exemplified by $C$. managuense, then taxonomic, ecological, and evolutionary analyses of "species flocks" may be in need of revision. However, Old World cichlids may be less phenotypically plastic than New World cichlids, and this may contribute to the observed differences in speciation rate and degree of endemism.
\end{abstract}

Received September 29, 1986. Accepted May 30, 1987

In number of species and in their ecological diversity, the cichlid fishes of the great African lakes (Tanganyika, Malawi, and Victoria) are unrivaled examples of vertebrate adaptive radiations. In these lakes, cichlids have formed "species flocks" (references in Echelle and Kornfield [1984]) with more than 300 endemic, coexisting, morphospecies. Speciation is thought to have occurred very rapidly. Some researchers (Fryer et al., 1983, 1985) consider cichlid species flocks to be better examples for punctuated modes of evolution than the molluscs of the Turkana Basin (Williamson, 1981, 1985). There is, however, considerable controversy over which evolutionary and ecological mechanisms can account for the origin and maintenance of the existing species assemblages (e.g., Kosswig, 1947, 1963; Fryer, 1965; Lowe-McConnell, 1969; Fryer and Iles, 1972; Greenwood, 1974, 1981; McKaye, 1980; Dominey, 1984; references in Echelle and Kornfield [1984]).

Although there is no agreement on a particular mode of speciation for the African species flocks, most researchers seem to assume narrow morphological adaptation with little phenotypic variation (e.g., van Oijen et al., 1981; van Oijen, 1982). Studies that explicitly examined the extent of intraspecific morphologic variation in cichlids are rare. Nevertheless, most studies implicitly assume very little morphological variation, and researchers seem to neglect the possibility of the existence of polymorphisms, because, among other characters, differences in colors of breeding males, bathymetric distributions, small differences in body proportions, and dentition are used as taxonomic characters to describe new species (van Oijen et al., 1981; Hoogerhoud et al., 1983). These traits are believed to have ecological significance and to be subject to natural selection (van Oijen, 1982).

Despite continuous interspecific morphological variation in their feeding apparatus, cichlids are divided into "functional groups" (Barel, 1983). The jaws of "biters" are hypothesized to inflict a relatively more powerful bite than those of "suckers," who suck prey directly into the buccal cavity without prior manipulation by the jaws. Barel (1983) coined these terms based on a morphological analysis of African cichlids. He deduced the mode of feeding (function) from morphology (form). This supposes a tight cor- 
relation of form and function; however, cichlids are known for their ability to modulate feeding behavior (e.g., Liem, 1978, 1979). Barel's terminology implies functional aspects of the cichlid's morphology, which have not been tested. I will therefore use the terms "obtusorostral" (from the Latin obtutus [blunt, dull] rostrum [snout]) for a biter morphology and "acutorostral" (from the Latin acutus [pointed, sharp]) for a sucker morphology. These terms describe the shape of the trophic morphology.

The categorization is not dichotomous but continuous and labels hypothetical pure endstages along a morphological continuum. The two types can be distinguished morphometrically: obtusorostral cichlids have i) relatively shorter lower jaws, ii) shorter snouts, iii) steeper and shorter ascending processes of the premaxillary bones, iv) shorter and more ventrally directed ethmoid regions of the neurocranium, and $v$ ) deeper adductor mandibulae muscles. The angle of the snout is steeper in obtusorostral cichlids. As a result, the gape of obtusorostral cichlids is not as wide, and the jaws cannot be protruded as far as in the acutorostral cichlids. This denomination of the trophic morphology of cichlids may have functional implications, which remain to be tested, and may be applicable to other groups of perciform fishes (Liem, pers. comm.).

Laboratory-reared and field-collected specimens of the New World predatory cichlid Cichlasoma managuense show an ontogenetic transformation from obtusorostral to acutorostral morphology (see ontogenetic trajectory of group I in Fig. 5). This pattern may suggest that the biting mode predominates early in ontogeny, with the suction mode predominating later in life, but the unambiguous assignment of feeding modes to these shape categories must be delayed until high-speed filming of the feeding events of the fish has been done.

During biting, the predator moves while the prey remains stationary, and prey is manipulated with the oral jaws. In suction feeding, the mouth of the predator expands rapidly, drawing water and prey into the buccal cavity; the prey is moved into the predator's mouth at a speed faster than the approaching speed of the predator.

It is commonly thought that morpholog- ical characters are more stable than behavioral characteristics of species and that behavioral changes precede morphological ones during speciation (Wiens 1977; Lauder, 1983; Liem and Kaufman, 1984; Sage et al., 1984). The dazzling variety of specialized morphological characters in African cichlids, nevertheless, is traditionally explained as a result of selection for trophic specialization which occurred during periods of low resource availabilities (reviewed in Greenwood [1984]). "Specialists" may be be more efficient in exploiting limited food sources (Wiens, 1977; but see Schoener [1971]).

The morphology of a cichlid may not reveal actual food habits, but it does permit reasonable predictions of the potential modes of feeding (how prey is caught). These alleged differences in functional morphology can have far-reaching ecological consequences. Some niches can be exploited only by biters and not by suckers and vice versa (van Oijen et al., 1981). However, in the Neotropical piscivorous Cichlasoma dovii ontogenetic shifts in stomach contents are not accompanied by large ontogenetic changes in morphology. C. dovii shows little intrapopulational phenotypic variation (Meyer, unpubl.). Evidence has accumulated from studies of functional morphology (Liem, 1973, 1978, 1979, 1980; Liem and Osse, 1975; Liem and Kaufman, 1984) and ecology (e.g., Greenwood, 1967; Hoogerhoud et al., 1983; McKaye and Marsh, 1983) that cichlids are more opportunistic feeders than had been assumed previously. Cichlids can modify their feeding modes in accordance with the location and type of the prey in the water column and switch to more diverse diets if particular prey species become abundant.

\section{Morphological Variation in Cichlid Fishes}

Despite the recent increase in accounts of "ecological plasticity" in Old World cichlids, reports of morphological variation in Old World cichlid species have been published for only two species (Astatoreochromis alluaudi [Greenwood, 1965; Hoogerhoud, 1986] and Haplochromis squamipinnis [Witte, 1984]), and only one trophic polymorphism is known in New World 
cichlids (Cichlasoma minckleyi [Sage and Selander, 1975; Kornfield et al., 1982; Kornfield and Taylor, 1983]). A systematic approach to the study of phenotypic plasticity in cichlid fishes is needed.

Because considerable morphological variation exists in natural populations of $C$. managuense (Meyer, unpubl.), I suspected that environmental factors influence the phenotypic expression of morphology in this species. I therefore examined the influence of diet on the phenotype during ontogeny in $C$. managuense by raising split broods of full siblings on different diets in the laboratory.

\section{MAterials AND Methods}

The male of the spawning pair was caught in Lago de Masaya in Nicaragua and the female was the daughter of a wild-caught fish from the same location. Young fish of the same lab-spawned brood were assigned randomly to one of two groups: group I was fed nauplii of Artemia salina, and group II was fed commercially available flake food and lab-reared nematode worms. The spawning occurred in July 1983.

These diets were employed because they are similar to diets that have been used in two laboratory studies on morphological variation in African cichlids by Greenwood (1965) and Witte (1984). The nauplii of $A$. salina are known to be nutritionally well balanced and are frequently used by commercial fish breeders. Nauplii and adults of A. salina are probably nutritionally similar. The flake food (Kordon products) was assumed to be nutritionally sufficient. The nematodes were reared in the laboratory on a substrate that was supplemented with a multivitamin preparation. Nutritional deficiencies were unlikely. The fish were fed ad libitum once daily, and the maintenance conditions were the same for both groups.

The fish of both groups received their respective diets for eight months after the onset of feeding, two weeks after spawning. They were then X-rayed for the first time to record their morphology at that stage of ontogeny. The diets of the fish of both groups were then switched to adult $A$. salina, which are considerably larger and more evasive than nauplii. The fish were $\mathrm{X}$-rayed again after feeding on this new diet for two weeks

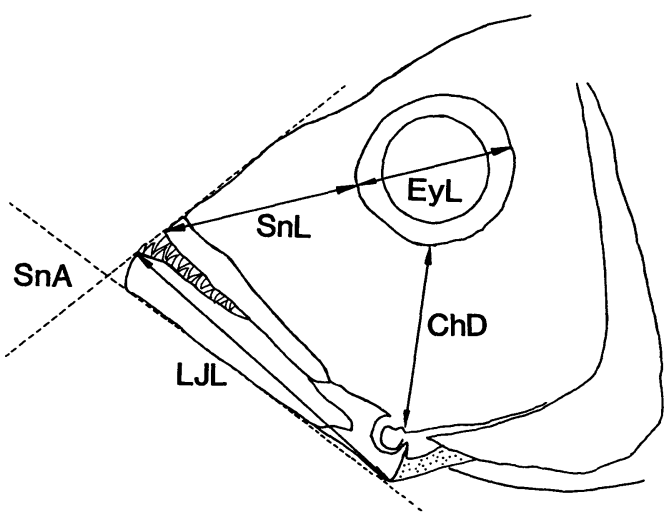

FIG. 1. Semischematic diagram (adapted from Barel et al. [1977]) of a cichlid head depicting measurements taken in this study, as defined by Barel et al. (1977). See legend of Table 1 for an explanation of abbreviations.

(second X-ray). The third X-ray was taken after feeding on adult $A$. salina for eight months at the total age of 16.5 months. A control group of group II with nine specimens was maintained on a flake-food diet for 17 months and then X-rayed. The youngest age of maturity under laboratory conditions is around 12 months (pers. observ.).

All fish were lightly anaesthetized with phenoxyethanol during the X-ray procedure. The X-ray procedure is not believed to harm the fish (Meyer, unpubl.), and groups were subjected to the same treatment. There were 11 fish in group I and 16 fish in group II at the first two X-rays. At the third X-ray, the sample size of group II was reduced to 11 , due to death of five specimens.

Morphological measurements made from the $\mathrm{X}$-rays were standard length, head length, snout length, eye length, lower jaw length, cheek depth, and snout acuteness (Fig. 1). They were measured as defined by Barel et al. (1977), although they were not measured directly from specimens but, rather, from $\mathrm{X}$-rays (Meyer, unpubl.). These measurements and ratios of measurements are important predictors for the categorization of fish into obtusorostral and acutorostral types (Barel, 1983). The young fish were not measured at the beginning of the experiment, because it is difficult to measure such small fish (less than $8 \mathrm{~mm}$ in total length) without harming them. A Gaussian distribution of 

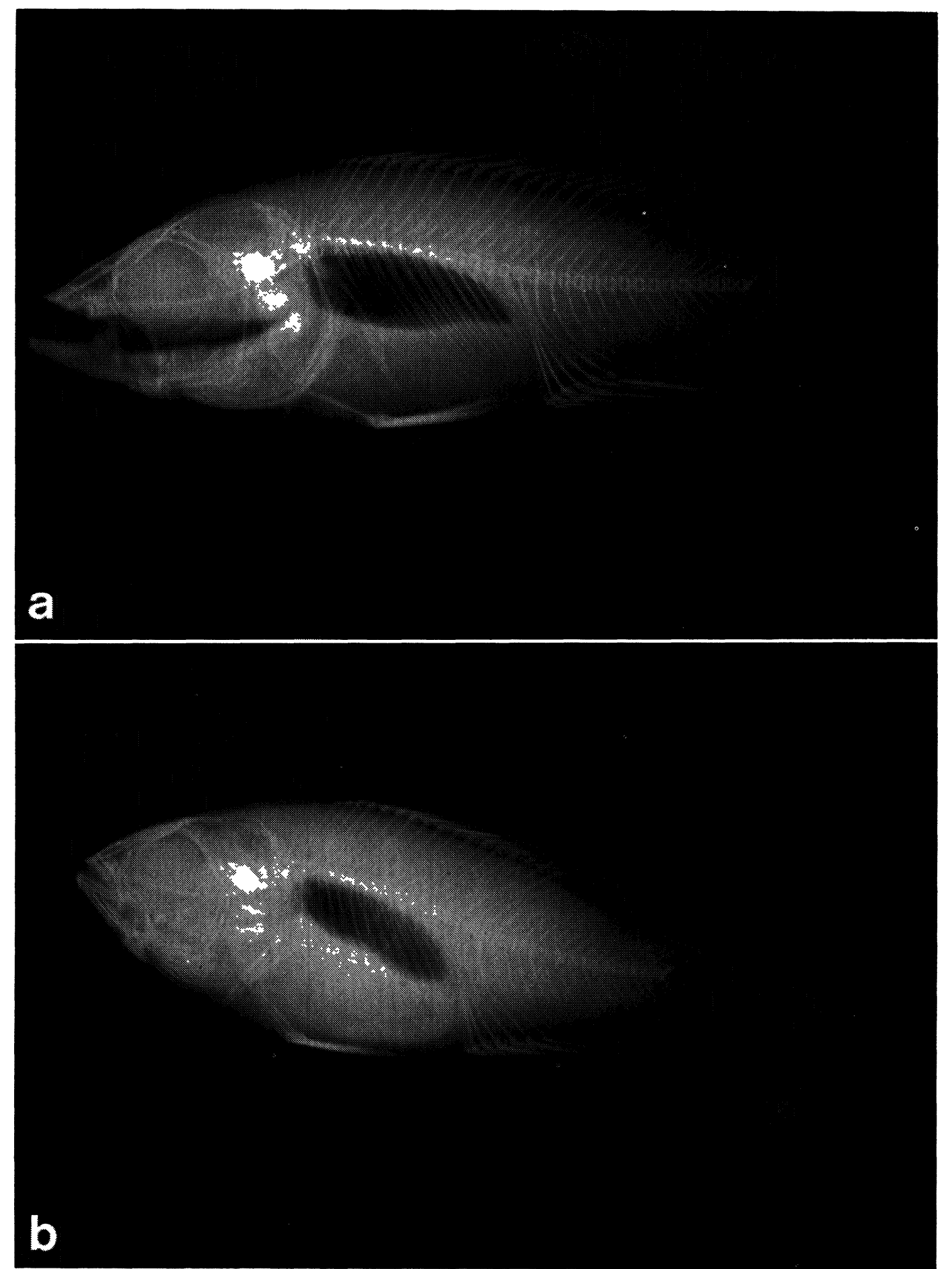

Fig. 2. First X-rays of a) group I fish and b) group II fish, after eight montins of feeding on different diets. Group I fish show the acutorostral morphology, and group II fish exhibit a more obtusorostral morphology. 
TABLE 1. Morphological measurements of the three X-rays of both groups of fish. SL is standard length (mm), HL is head length, ChD is cheek depth, LJL is lower jaw length, EyL is eye length, SnL is snout length, and $\mathrm{SnA}$ is snout acuteness. Except in the cases of SL and SnA (degrees), measurements were first made in $\mathrm{mm}$ and then allometrically adjusted (see Materials and Methods for details). The diet was changed after the first X-ray. Multiple comparisons required adjustment of the type-I error rate using Sívăk's multiplicative inequality (Sokal and Rohlf, 1981). The most conservative estimate of the smallest $t$ value at an adjusted $P=0.05$ type-I error rate was $t=3.443$ (d.f. $=21, k=21)$.

\begin{tabular}{|c|c|c|c|c|c|c|}
\hline \multirow[b]{2}{*}{ Character } & \multicolumn{2}{|c|}{ Group I } & \multicolumn{2}{|c|}{ Group II } & \multicolumn{2}{|c|}{ Comparison of means } \\
\hline & $\bar{x}$ & SD & $\bar{x}$ & SD & $t$ & $P$ \\
\hline \multicolumn{7}{|c|}{ First X-ray (8.5 months): } \\
\hline SL & 31.47 & 2.59 & 26.87 & 3.49 & 3.73 & 0.001 \\
\hline $\mathrm{HL}$ & 12.56 & 0.28 & 12.00 & 0.62 & 2.80 & 0.010 \\
\hline ChD & 2.66 & 0.18 & 2.43 & 0.30 & 2.23 & 0.029 \\
\hline LJL & 7.77 & 0.24 & 6.65 & 0.36 & 8.97 & 0.000 \\
\hline EyL & 4.83 & 0.16 & 4.30 & 0.23 & 6.64 & 0.000 \\
\hline $\mathrm{SnL}$ & 3.18 & 0.19 & 2.68 & 0.20 & 6.56 & 0.000 \\
\hline $\operatorname{Sn} A$ & 68.91 & 2.59 & 79.91 & 2.86 & 8.39 & 0.000 \\
\hline \multicolumn{7}{|c|}{ Second X-ray (9 months): } \\
\hline SL & 34.63 & 3.46 & 31.28 & 4.38 & 2.12 & 0.044 \\
\hline $\mathrm{HL}$ & 12.50 & 0.30 & 12.25 & 0.49 & 1.50 & 0.145 \\
\hline $\mathrm{ChD}$ & 2.79 & 0.22 & 2.55 & 0.21 & 2.86 & 0.008 \\
\hline LJL & 7.62 & 0.12 & 6.98 & 0.49 & 4.29 & 0.000 \\
\hline EyL & 4.80 & 0.21 & 4.53 & 0.22 & 3.16 & 0.004 \\
\hline $\mathrm{SnL}$ & 3.13 & 0.24 & 2.75 & 0.24 & 3.98 & 0.001 \\
\hline $\mathrm{SnA}$ & 70.18 & 2.08 & 75.03 & 3.84 & 3.80 & 0.001 \\
\hline \multicolumn{7}{|c|}{ Third X-ray (16.5 months): } \\
\hline SL & 46.58 & 4.99 & 44.21 & 6.29 & 0.98 & 0.339 \\
\hline $\mathrm{HL}$ & 12.49 & 0.30 & 12.47 & 0.29 & 0.13 & 0.900 \\
\hline $\mathrm{ChD}$ & 2.53 & 0.15 & 2.57 & 0.15 & 0.60 & 0.599 \\
\hline LJL & 7.02 & 0.21 & 6.93 & 0.35 & 0.80 & 0.433 \\
\hline EyL & 4.45 & 0.21 & 4.68 & 0.23 & 2.20 & 0.040 \\
\hline $\mathrm{SnL}$ & 2.85 & 0.19 & 2.72 & 0.10 & 2.11 & 0.048 \\
\hline $\mathrm{SnA}$ & 65.80 & 2.44 & 69.73 & 3.30 & 3.17 & 0.005 \\
\hline
\end{tabular}

morphological characters was assumed at the onset of the experiment.

Most measures of shape covary in some way with size. Therefore heterogeneity in the sizes across samples will result in heterogeneity in shape (Strauss, 1984; Wilhelm, 1984). It is necessary to compare the shape between groups free of the confounding effect of size on shape; therefore, one needs to adjust the data. With the exception of standard length and snout acuteness, the data were adjusted with Thorpe's (1975) method of allometrically adjusting shape to size. For the data in Table 1, the pooled group allometric coefficients were calculated and used to adjust the data. For the data in Table 2, the common within-group allometric coefficients were calculated for group II at the first X-ray and the control group at 17 months. The equations are given in Thorpe (1975) and Reist $(1985,1986)$.
This method was found to be one of two univariate methods that removed shape from the effects of size adequately and without detrimental statistical effects (Reist, 1985, 1986). Comparisons between the two groups of all three X-rays were done with one-way ANOVAs. All statistical tests were done with the SYSTAT statistical package (Wilkinson, 1986).

\section{RESULTS}

After the fish in both groups had been fed different diets for the first eight months, almost all measurements were significantly different for the two groups (Table 1: first $\mathrm{X}$-ray). Only the differences in head length and cheek depth of the allometrically adjusted data were not statistically significant. At 8.5 months of age, group I fish exhibited the ontogenetically more advanced acutorostral shape (Fig. 2a), and group II fish had 


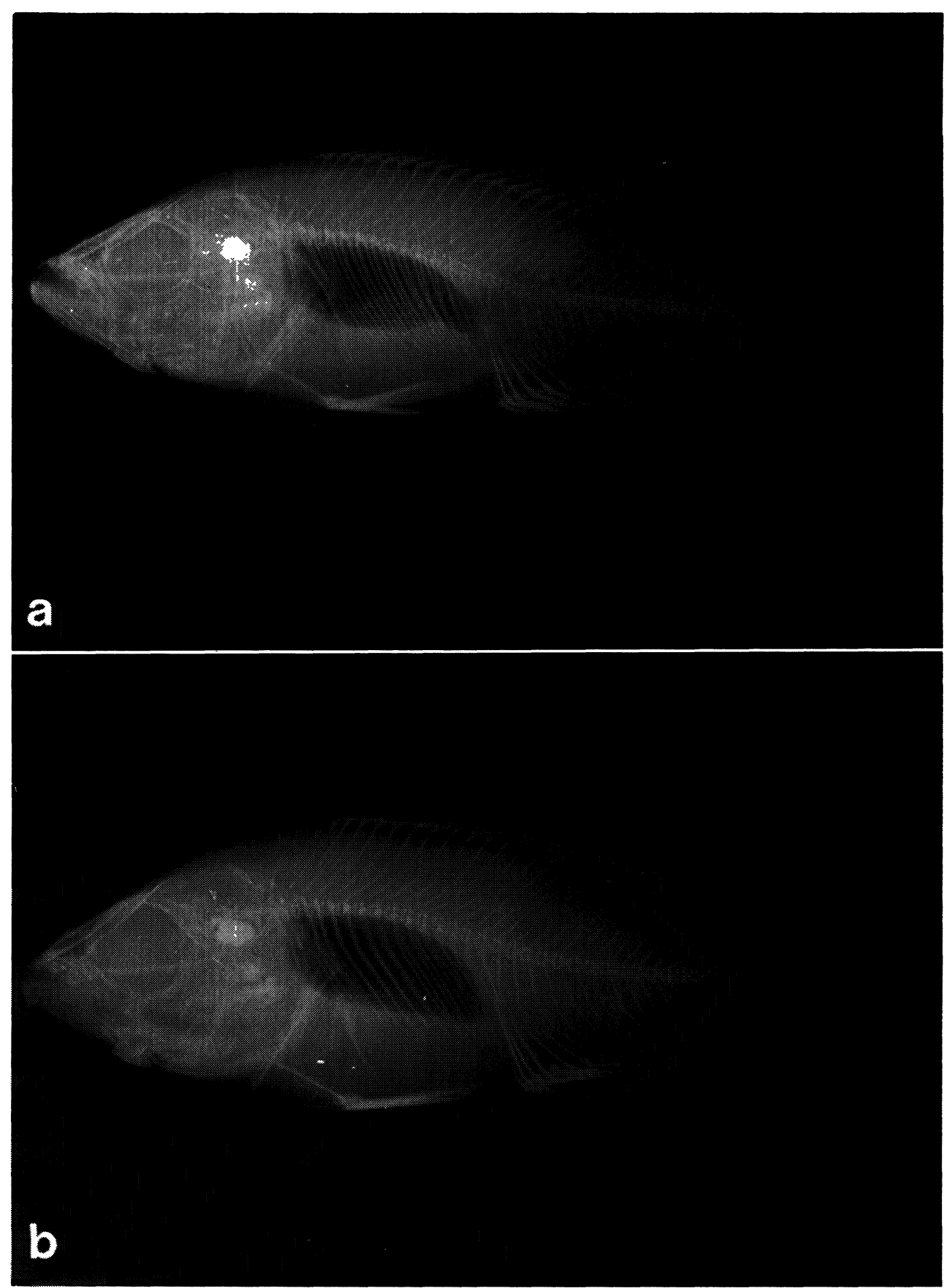

Fig. 3. Third X-rays of a) group I fish and b) group II fish after eight months of feeding on the same diet (age $=16.5$ months). Fish of both groups show the acutorostral morphology. 


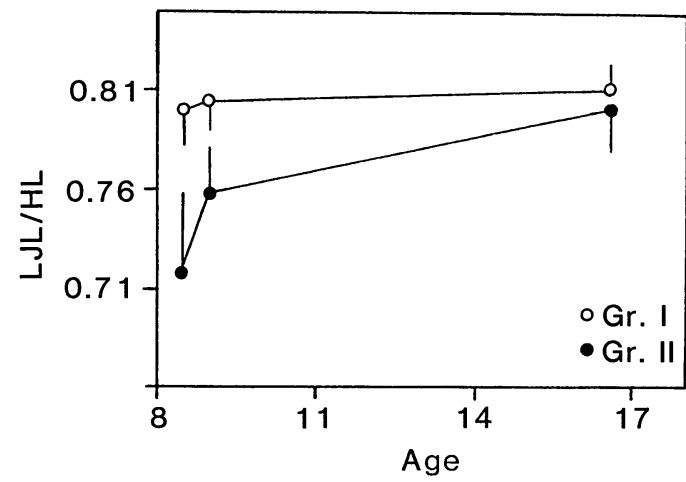

Fig. 4. Mean ontogenetic trajectories of the two groups. The log-transformed ratios of the lower jaw length to head length are graphed as a function of age. Vertical bars represent one standard deviation. The diet switch to a common diet and feeding mode for both groups occurred after the first X-ray at the age of 8.5 months. Note that in group I the change of the relative length of the lower jaw is much smaller than in group II. The morphology of group II changes quickly from an obtusorostral to an acutorostral morphology. The ontogenetic trajectory of group II approaches that of group I. See also the LJL/HL of the control group, which was maintained on a flake-food diet for 17 months (Table 2). The morphology of this group remains largely obtusorostral.

a more obtusorostral shape (Fig. 2b). The measurement in cheek depth went in the opposite direction of Barel's (1983) classification.

Following the switch to the new diet, the ontogenetic trajectories (Gould, 1977; Alberch et al., 1979) of group II began to converge rapidly on the phenotype of group I (Table 1: second X-ray). After feeding for two weeks on the same diet, at the age of 9 months, the differences in head length, cheek depth, and eye length became statistically insignificant (Table 1: second X-ray). After both groups had received the same diets for eight months, at the age of 16.5 months, all morphological measurements followed the same pattern and became statistically indistinguishable between groups (Table 1: third X-ray). Fish of both groups looked almost identical by the time of the third X-ray (Fig. 3). Only snout acuteness was still somewhat different between the groups (Table 1: third X-ray). Snout acuteness and cheek depth had the largest measurement error, particularly when measured from $\mathrm{X}$-rays (Meyer, unpubl.).

Nine $C$. managuense, of a different group but from the same parents, were kept on a

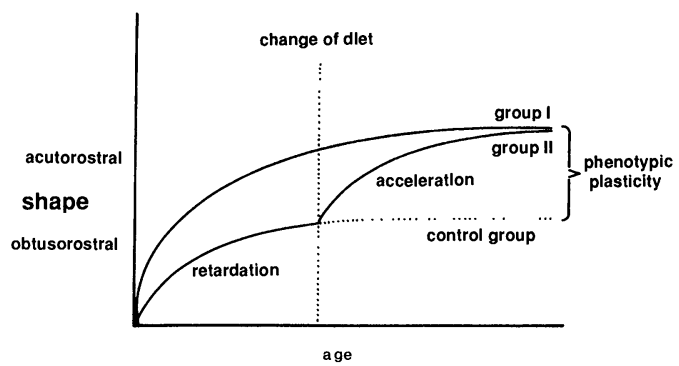

FIG. 5. Qualitative model showing the ontogenetic trajectories and the assumed heterochronic processes responsible for the observed developmental patterns (applying heterochronic terminology to intraspecific ontogenetic events). At 8.5 months of age, before the diet change, the fish in group II show a "paedomorphic" (obtusorostral) morphology due to the process of neoteny, which retards the shape growth-rate relative to the "normal" (acutorostral) developmental trajectory of group I. The acceleration in shape growthrate after the diet was changed is relative to group I, which remained acutorostral in shape, and to the control group, which continued to feed on flake food and remained obtusorostral in shape.

flake-food diet for 17 months. The phenotypes of these fish remained obtusorostral. In Table 2, I compare the allometrically adjusted measurements of this group with the obtusorostral shape of group II at the first $\mathrm{X}$-ray. The fish do not differ in lower jaw length, eye length, or snout length, are somewhat different in snout acuteness, but differ in head length and cheek depth. The relative lower jaw length in this group is obtusorostral $(\bar{x}=0.749, \mathrm{SE}=0.031$; see legend of Fig. 4) and not significantly different from group II at the age of 8.5 months. Thus, if feeding on the diet of group II is continued after 8.5 months, convergence to a common mature phenotype will not occur (stippled line in Fig. 5), and the mature phenotypes will therefore be different. However, a diet change in 8.5-month-old $C$. managuense from $A$. salina to flake food does not seem to change their phenotype to an obtusorostral morphology, and the fish remain on the acutorostral ontogenetic trajectory (Meyer, unpubl.).

\section{DISCUSSION}

\section{Heterochrony and Phenotypic Plasticity}

The dietary differences and possible differences in feeding mode seem to have caused differential timing of developmental events. Below, I present a qualitative model 
to describe the heterochronic processes (Alberch et al., 1979) that I believe to have occurred and their relation to phenotypic plasticity and canalization of development (Figs. 4, 5).

If one visualizes a growing organism as a point moving in a shape, size, and age space, one obtains ontogenetic trajectories by connecting those points (Gould, 1977; Alberch et al., 1979). The ontogenetic trajectory of group I is the "normal" developmental pathway: most Cichlasoma managuense pass quickly through the obtusorostral stage (Meyer, unpubl.). The morphology of group I did not change much among the three $\mathrm{X}$-rays; the fish reached their mature acutorostral shape early in ontogeny (Table 1; Figs. 4, 5). The feeding mode of group I probably did not change throughout the study.

The rate of change in shape of group II was apparently retarded initially. The shift in diet (and possibly in feeding mode) that the fish in group II experienced at 8.5 months caused an acceleration in the rate of change in shape. Flake food and living brine shrimp will be captured by means of different feeding modes (Liem, pers. comm.). This led to a convergence of the phenotype of group II on the phenotype of group I (acutorostral morphology) after the second X-ray (at maturity; Figs. 4, 5). This convergence is confirmed by the unaltered obtusorostral shape of fish maintained on the flake-food diet for 17 months (Table 2).

A model like this, combining heterochrony with intraspecific morphological variation, could easily be modified to depict other environmental perturbations (e.g., shifts in temperature during development or shifts in prey availabilities) that may cause conversions on common phenotypes from originally different phenotypes or divergence of originally similar phenotypes into different morphologies.

\section{Proximate Mechanisms of Phenotypic Plasticity}

A mechanism that may account for the extremely fast bone remodelling needed to give the results reported here was documented by Rubin and Lanyon (1984). They showed that even low frequencies of dynamic loads on bone can result in pro- nounced remodelling of bone structure. Also Hall (e.g., 1983, 1984) investigated epigenetic mechanisms that underlie heterochronic events. Other environmental factors have been shown to play an important role in the phenotypic expression of morphology, especially in plants (Bradshaw, 1965; see reviews in Schlichting [1986] and Sultan [1987]) and invertebrates (Brooks, 1965; Bernays, 1986; Govind and Pearce, 1986; Lively, 1986), but also in amphibians (Collins and Cheek, 1983), birds (James, 1983), and mammals (Patton and Brylski, 1987).

The environmental component of trophic polymorphisms in fishes (e.g., Greenwood, 1965; Roberts, 1974; Vrijenhoek, 1978; Turner and Grosse, 1980; Kornfield and Taylor, 1983; Grudzien and Turner, 1984) is largely unknown (but see Hoogerhoud [1986]). Often the question of conspecificity of these morphs is unresolved (e.g., Roberts, 1974), and field observations of spawnings are desirable to confirm their validity as biological species. Ontogenetic changes and polymorphisms of intestinal lengths and their ecological correlates have been studied in fishes (e.g., de Moor et al., 1986). In the case of the Arctic charr Salvelinus alpinus, some of the morphologic variation seems to be phenotypic. Distinct morphs with different life-history strategies occur in this species (Vrijenhoek et al., 1987). However, controversy over their status as a single species persists (Savvaitova, 1973, 1983; Johnson, 1980; Hindar and Jonsson, 1982; Jonsson and Hindar, 1982; Hindar, 1986; Nordeng, 1983).

\section{Implications of Phenotypic Plasticity in Cichlasoma managuense}

The morphological variation in the oral jaws of this Neotropical species is far larger than the previous account of the extent of phenotypic plasticity in oral jaws in an African cichlid fish (Witte, 1984). The two groups (at the first X-ray) differ in some features more than do some sister species or even genera of African cichlids (Hoogerhoud et al., 1983). The case of Cichlasoma managuense may serve as a cautionary note to taxonomists describing new species based on small differences in body proportions. If one searches for optimally adapted designs, 
TABLE 2. Morphological measurements of the X-rays of group II fish after eight months on their diet and of the control group, which was kept on the flake-food diet for 17 months. Abbreviations of traits are as given in Table 1. Except in the cases of SL (mm), SnA (degrees), and the relative lower jaw length (LJL/HL), measurements were first made in mm and then allometrically adjusted (see Materials and Methods for details). LJL/HL (the ratio of log-transformed measurements) are given to allow comparison with data in Figure 4. Multiple comparisons required adjustment of the type-I error rate using Sívăk's multiplicative inequality (Sokal and Rohlf, 1981). The most conservative estimate of the smallest $t$ value at an adjusted $P=0.05$ type-I error rate was $t=2.931$ (d.f. $=24, k=7$ ).

\begin{tabular}{|c|c|c|c|c|c|c|}
\hline \multirow[b]{2}{*}{ Character } & \multicolumn{2}{|c|}{$\begin{array}{c}\text { Group II } \\
(8.5 \text { months })\end{array}$} & \multicolumn{2}{|c|}{$\begin{array}{l}\text { Control group } \\
\text { (17 months) }\end{array}$} & \multicolumn{2}{|c|}{ Comparison of means } \\
\hline & $\bar{x}$ & SD & $\bar{x}$ & SD & $t$ & $P$ \\
\hline SL & 26.87 & 3.49 & 48.40 & 20.24 & 4.21 & 0.000 \\
\hline $\mathrm{HL}$ & 11.00 & 0.54 & 12.37 & 1.16 & 4.06 & 0.000 \\
\hline ChD & 2.21 & 0.27 & 3.07 & 0.86 & 3.70 & 0.001 \\
\hline LJL & 6.06 & 0.33 & 5.94 & 0.65 & 0.62 & 0.544 \\
\hline EyL & 3.97 & 0.21 & 4.12 & 0.36 & 1.89 & 0.071 \\
\hline SnL & 2.41 & 0.19 & 2.69 & 0.37 & 2.52 & 0.019 \\
\hline $\mathrm{SnA}$ & 79.91 & 2.86 & 74.33 & 3.08 & 2.93 & 0.007 \\
\hline $\mathrm{LJL} / \mathrm{HL}$ & 0.71 & 0.44 & 0.75 & 0.09 & 1.34 & 0.192 \\
\hline
\end{tabular}

one may find that, because of the phenotypic response to environmental fluctuations, a given species may seem to be adapted to more than one feeding task.

If the effects of diet on morphology are similar in other cichlids, as they might be in Cichlasoma citrinellum (see below), then phenotypic plasticity in natural populations may ultimately be a reflection of differential patterns of resource availabilities and/or prey choice, which are known to occur (e.g., Hoogerhoud et al., 1983; Katunzi, 1983) and which may influence mature phenotypes.

\section{The Ubiquity of Phenotypic Plasticity and Polymorphisms in Fishes}

The degree of morphological plasticity within fishes may be larger and much more widespread than has been previously assumed (but see Turner and Grosse [1980]; Vrijenhoek et al., 1987). Trophic polymorphism in the pharyngeal jaw structure has been found in another Neotropical cichlid species, Cichlasoma citrinellum (Meyer, unpubl.). The variant forms resemble the case of the only known trophic polymorphism in New World cichlids, C. minckleyi (Sage and Selander, 1975; Kornfield and Taylor, 1983). Differences in the pharyngeal jaws of morphs in these two species are as large as the ones used by Greenwood (1980) to separate two genera (Gaurochromis and Labidochromis) of African cichlids. I am currently testing the importance of environ- mental components in the trophic polymorphism in C. citrinellum.

\section{Phenotypic Variation and Speciation}

Plasticity could be expressed either as distinct morphs through "developmental conversion" or as continuous morphological variation through "phenotypic modulation" (sensu Smith-Gill, 1983). Trophic polymorphism has been hypothesized to be an intermediate step during speciation of cichlids (Sage and Selander, 1975). Therefore, if African cichlids were to exhibit a comparable degree of phenotypic plasticity', evolutionary biologists would have to consider intraspecific variation in morphology and in ecology, as well as in behavior (particularly in feeding and mate choice) when attempting to model the rapid evolution of the cichlid species flocks. One might hypothesize that many more African species will be found to be polymorphic, and fewer species than previously assumed may exist.

However, the amount of phenotypic plasticity in the oral jaws in Old World cichlids reported by Witte (1984) is small in comparison to the one reported here. If Witte's results are typical of the extent of phenotypic plasticity in African cichlids, then African cichlids may be less plastic than American cichlids. This hypothesis calls for research on the extent of phenotypic plasticity of more species from both hemispheres. (I assume that the taxonomic criteria for assigning species rank to taxa is the 
same in the Old World as it is in the New World.)

This difference in plasticity would then be one additional factor contributing to the observed contrasting rates of speciation and degrees of endemism between Old World and New World cichlids. Plasticity may be a form of inertia against speciation. This is in line with the traditional view that phenotypically plastic traits evolve slower than canalized traits (e.g., Sultan, 1987; but see Stearns [1983]).

Not all groups of African cichlids exhibit the same degree of endemism in the East African rift lakes: the Tilapia are much less species-rich than other groups of Old World cichlids. For example, in contrast to haplochromine cichlids, they speciated at significantly lower rates from their riverine ancestors. Tilapine cichlids are known for their adaptability to environmental perturbations and the ease with which they hybridize. They have been introduced in many habitats worldwide and they have actually invaded marine habitats such as coral reefs. I would predict tilapian cichlids to be more phenotypically plastic than, e.g., haplochromine cichlids and other groups of African cichlids with a high degree of endemism.

\section{Developmental Pathways and Phenotypic Plasticity}

Most African cichlids differ from Neotropical cichlids in their predominant modes of reproduction. Most African cichlids are mouthbrooders, which have few precocial offspring (which are well developed at the onset of feeding), but most Neotropical cichlids are substrate spawners, which have far more altricial offspring (references in Balon [1985]; Meyer, 1987). This difference in mode of reproduction and developmental stage during first feeding may be correlated with different developmental pathways, which may in turn be related to differing degrees of canalization of development. However, Tilapia also are mouthbrooders and would tend to refute this idea.

Contrasting degrees of phenotypic plasticity may result from differing degrees of canalization or differing strengths of ontogenetic buffers during ontogeny (Waddington, 1942; Waddington and Robertson,
1966; Katz and Lasek, 1978; Katz et al., 1981; Rendel, 1979; Alberch, 1982; references in Bonner [1982]).

The concepts of phenotypic plasticity, heterochrony, and evolutionary theory have not been unified. Attempts have been made to incorporate phenotypic plasticity into evolutionary theory (Via and Lande, 1985), and hypotheses about the importance of heterochrony in macroevolution have been advanced by Gould (e.g., 1977) and Alberch (e.g., 1980). Here, I have applied the concept of heterochrony, which advanced the understanding of some phenomena of interspecific morphological variation (ancestor-descendent relationships), to intraspecific epigenetic morphological variation. Investigations of the relationship between phenotypic variation and speciation rates are just starting (Hoffman, 1982). This area of research deserves more effort and promises fruitful insights.

The results of this study demonstrate the large potential for environmental influences on the phenotype in Cichlasoma managuense. These experiments suggest a feedback system between diet, feeding mode, and morphology in cichlid fishes. Unfortunately, they do not provide information on the respective influence of diet and feeding mode. Experiments to isolate these factors are underway: fish are raised on nutritionally identical diets that are presented in manners that require different feeding modes for ingestion. I am testing the exclusive influence of the feeding mode on morphology, a feedback system which had been neglected.

\section{ACKNOWLEDGMENTS}

I thank C. D. N. Barel, M. J. F. M. van Hasselt, A. J. Ribbink, and F. Witte for their inspection of the X-rays and their discussion of the findings. I thank C. Barel, G. Barlow, P. Brylski, E. Grosholz, R. Hoogerhoud, K. Liem, L. Lugar, E. Mayr, S. Naeem, K. Nishikawa, L. Parenti, J. Patton, G. Roderick, W. Sousa, M. Stiassny, D. Wake, M. Wake, P. Wimberger, F. Witte, and one anonymous reviewer for their helpful comments and discussions. This study was funded in part by NSF grant BNS 794081 and NIH grant HD18496 to G. W. Barlow. I thank the German and the Amer- 
ican Fulbright Commissions, the Organization for Tropical Studies, the American Cichlid Association, Sigma Xi, and the University of California at Berkeley for grants and fellowships that financially supported this study. I thank K. Liem, M. Stiassny, and $\mathrm{K}$. Hartel at Harvard University for their hospitality during part of this study and J. Patton and R. Vrijenhoek for providing me with unpublished manuscripts.

\section{Literature Cited}

Alberch, P. 1980. Ontogenesis and morphological diversification. Amer. Zool. 20:653-667.

- 1982. The generative and regulatory roles of development in evolution, pp. 19-36. In D. Mossakowski and G. Roth (eds.), Environmental Adaptation and Evolution. Gustav Fischer-Verlag, Stuttgart, W. Ger.

Alberch, P., S. J. Gould, G. F. Oster, AND D. B. WAKE. 1979. Size and shape in ontogeny and phylogeny. Paleobiology 5:296-317.

BALON, E. K. (ed.). 1985. Early Life Histories of Fishes: New Developmental, Ecological and Evolutionary Perspectives. Junk, Dordrecht, Neth.

BAREL, C. D. N. 1983. Towards a constructional morphology of cichlid fishes, (Teleostei, Perciformes). Neth. J. Zool. 33:357-424.

Barel, C. D. N., M. J. P. van Oijen, F. Witte, AND L. M. WitTe-MAAs. 1977. An introduction to the taxonomy and morphology of the haplochromine Cichlidae from Lake Victoria. Neth. J. Zool. 27: 333-389.

BERnAYS, E. A. 1986. Diet-induced head allometry among foliage-chewing insects and its importance for graminivores. Science 231:495-497.

BoNNER, J. T. (ed.). 1982. Evolution and Development. Springer-Verlag, Berlin, W. Ger.

BRADSHAw, A. D. 1965. Evolutionary significance of phenotypic plasticity in plants. Adv. Genet. 13:115155.

Brooks, J. L. 1965. Predation and relative helmet size in cyclomorphic Daphnia. Proc. Nat. Acad. Sci. USA 53:119-126.

Collins, J. P., AND J. E. Cheek. 1983. Effect of food and density on development of typical and cannibalistic salamander larvae in Ambystoma tigrinum nebulosum. Amer. Zool. 23:77-84.

DE MoOR, F. C., R. C. Wilkinson, AND H. M. Herbst. 1986. Food and feeding habits of Oreochromis mosambicus (Peters) in hypertrophic Hartbeespoort Dam, South Africa. S. Afr. J. Zool. 21:170176.

Dominey, W. J. 1984. Effects of sexual selection and life history on speciation: Species flocks in African cichlids and Hawaiian Drosophila, pp. 231-249. In A. A. Echelle and I. Kornfield (eds.), Evolution of Fish Species Flocks. Univ. Maine Press, Orono.

ECHElle, A. A., AND I. Kornfield (eds.). 1984. Evolution of Fish Species Flocks. Univ. Maine Press, Orono.

FrYer, G. 1965. Predation and its effects on migra- tion and speciation in African fishes: A comment. Proc. Zool. Soc. Lond. 144:301-310.

Fryer, G., P. H. Greenwood, AND J. F. Peake. 1983. Punctuated equilibria, morphological stasis and the palaeontological documentation of speciation; A biological appraisal of a case history in an African lake. Biol. J. Linn. Soc. 20:195-205.

- 1985. The demonstration of speciation in fossil molluscs and living fishes. Biol. J. Linn. Soc. 26:325-336.

Fryer, G., AND T. D. Iles. 1972. The cichlid fishes of the great lakes of Africa. T.H.F., Neptune City, NJ.

Gould, S. J. 1977. Ontogeny and Phylogeny. Belknap, Cambridge, MA.

Govind, C. K., AND J. Pearce. 1986. Differential reflex activity determines claw and closer muscle asymmetry in developing lobsters. Science 233:354 356.

GreENwood, P. H. 1965. Environmental effects on the pharyngeal mill of a cichlid fish, Astatoreochromis alluaudi and their taxonomic implications. Proc. Linn. Soc. Lond. 176:1-10.

- 1967. A revision of the Lake Victoria Haplochromis species (Pisces, Cichlidae) Part VI. Bull. Brit. Mus. Nat. His. Zool. 15:29-119.

1974. The cichlid fishes of Lake Victoria, East Africa: The biology and evolution of a species flock. Bull. Brit. Mus. Nat. His. Zool. Suppl. 6:1134.

- 1980. Towards a phyletic classification of the 'genus' Haplochromis (Pisces, Cichlidae) and related taxa. Part II: The species from Lake Victoria, Nabugabo, Edward, George and Kivu. Bull. Brit. Mus. Nat. Hist. Zool. 39:1-101.

. 1981. Species flocks and explosive evolution, pp. 61-74. In P. H. Greenwood and P. L. Forey (eds.), Chance, Change and Challenge-The Evolving Biosphere. Cambridge Univ. Press and Brit. Mus. Nat. Hist., London, U.K.

1984. African cichlids and evolutionary theories, pp. 141-154. In A. A. Echelle and I. Kornfield (eds.), Evolution of Fish Species Flocks. Univ. Maine Press, Orono.

Grudzien, T. A., AND B. J. Turner. 1984. Direct evidence that the Ilyodon morphs are a single biological species. Evolution 38:402-407.

HALL, B. K. 1983. Epigenetic control on development and evolution, pp. 353-379. In B. C. Goodwin, N. J. Holder, and C. C. Wylie (eds.), Development and Evolution. Cambridge Univ. Press, Cambridge, U.K.

. 1984. Developmental mechanisms underlying the formation of atavisms. Biol. Rev. 59:89124.

HINDAR, K. 1986. Genetic differentiation among local populations and morphotypes of Arctic charr, Salvelinus alpinus. Biol. J. Linn. Soc. 27:260-285.

HiNDAR, K., AND B. JonsSON. 1982. Habitat and food segregation of dwarf and normal Arctic charr ( $\mathrm{Sal}$ velinus alpinus) from Vangsvatnet Lake, western Norway. Can. J. Fish. Aquat. Sci. 39:1030-1045.

Hoffman, A. 1982. Punctuated versus gradual mode of evolution: A reconsideration. Evol. Biol. 15:411436.

Hoogerhoud, R. J. C. 1986. Taxonomic and eco- 
logical aspects of morphological plasticity in molluscivorous haplochromines (Pisces, Cichlidae). Ann. Mus. Roy. Afr. Centre Sci. Zool. 251:131134.

Hoogerhoud, R. J. C., F. Witte, And C. D. N. Barel. 1983. The ecological differentiation of two closely resembling Haplochromis species from Lake Victoria (H. iris and H. hiatus; Pisces, Cichlidae). Neth. J. Zool. 33:283-305.

JAMES, F. C. 1983. Environmental component of morphological differentiation in birds. Science 221: 184-186.

JoHnson, L. 1980. The Arctic charr, Salvelinus alpinus, pp. 15-98. In E. K. Balon (ed.), Charrs, Salmonid Fishes of the Genus Salvelinus. Junk, The Hague, Neth.

JonsSON, B., AND K. Hindar. 1982. Reproductive strategy of dwarf and normal Arctic charr (Salvelinus alpinus) from Vangsvatnet Lake, western Norway. Can. J. Fish. Aquat. Sci. 39:1404-1413.

KATUNZI, E. F. B. 1983. Seasonal variation in the food of a molluscivorous cichlid Haplochromis sauvagei Pfeffer 1896. Neth. J. Zool. 34:337-342.

KATZ, M. J., AND R. J. LASEK. 1978. Evolution of the nervous system: Role of ontogenetic mechanisms in the evolution of matching populations. Proc. Nat. Acad. Sci. USA 75:1349-1352.

Katz, M. J., R. J. LASEK, AND I. R. KaISERMAN-ABRAMOF. 1981. Ontophyletics of the nervous system: Eyeless mutants illustrate how ontogenetic buffer mechanisms channel evolution. Proc. Nat. Acad. Sci. USA 78:397-401.

Kornfield, I. L., D. C. Smith, P. S. Gagnon, And J. N. TAYLOR. 1982. The cichlid fish of Cuatro Cienegas Mexico: Direct evidence of conspecificity among distinct trophic morphs. Evolution 36:658664.

KoRNField, I. L., AND J. N. TAYloR. 1983. A new species of polymorphic fish, Cichlasoma minckleyi from Cuatro Cienegas, Mexico (Teleostei: Cichlidae). Proc. Biol. Soc. Wash. 96:253-269.

KosswiG, C. 1947. Selective mating as a factor for speciation in cichlid fish of East African lakes. Nature 159:238-244.

- 1963. Ways of speciation in fishes. Copeia 1963:238-244.

LAUDER, G. V. 1983. Neuromuscular patterns and the origin of trophic specialization in fishes. Science 219:1235-1237.

LIEM, K. F. 1973. Evolutionary strategies and morphological innovations: Cichlid pharyngeal jaws. Syst. Zool. 22:425-441.

- 1978. Modulatory multiplicity in the functional repertoires of the feeding mechanism on cichlid fishes. I. Piscivores. J. Morphol. 158:323-360.

- 1979. Modulatory multiplicity in the feeding mechanism in cichlid fishes, as exemplified by the invertebrate pickers of Lake Tanganyika. J. Zool. Lond. 189:93-125.

- 1980. Adaptive significance of intra- and interspecific differences in the feeding repertoire of cichlid fishes. Amer. Zool. 20:295-314.

LiEM, K. F., AND L. S. KAUfMAN. 1984. Intraspecific macroevolution: Functional biology of the polymorphic cichlid species Cichlasoma minckleyi, pp. 203-215. In A. Echelle and I. Kornfield (eds.), Evo- lution of Fish Species Flocks. Univ. Maine Press, Orono.

LiEM, K. F., AND J. W. Osse. 1975. Biological versatility, evolution, and food resource exploitation in African cichlid fishes. Amer. Zool. 15:427-454.

Lively, C. M. 1986. Predator-induced shell dimorphism in the acorn barnacle Chthalmalus anisopoma. Evolution 40:232-242.

Lowe-MCCONNELl, R. H. 1969. Speciation in tropical freshwater fishes. Biol. J. Linn. Soc. 1:51-75.

MCKAYE, K. R. 1980. Seasonality in habitat selection by the color morph of Cichlasoma citrinellum and its relevance to sympatric speciation in the family Cichlidae. Env. Biol. Fish. 5:75-78.

MCKAYE, K. R., AND R. MARSH. 1983. Food switching by two specialized algae-scraping cichlid fishes in Lake Malawi, Africa. Oecologia 56:245-248.

Meyer, A. 1987. First feeding success with two types of prey by the Central American cichlid fish, Cichlasoma managuense (Pisces, Cichlidae): Morphology versus behavior. Env. Biol. Fish. 18:127-134.

NoRDENG, H. 1983. Solution to the 'char problem' based on Arctic char (Salvelinus alpinus) in Norway. Can. J. Fish. Aquat. Sci. 40:1372-1387.

Patton, J. L., AND P. V. BRYlSKi. 1987. Pocket gophers in alfalfa fields: Causes and consequences of habitat-related body size variation. Amer. Natur. 130. In press.

REIST, J. D. 1985. An empirical evaluation of several univariate methods for size variation in morphometric data. Can. J. Zool. 63:1429-1439.

1986. An empirical evaluation of coefficients used in residual and allometric adjustments of size covariation. Can. J. Zool. 64:1364-1368.

ReNDEL, J. M. 1979. Canalization and selection, pp. 139-156. In J. N. Thompson and J. M. Thoday (eds.), Quantitative Genetic Variation. Academic Press, N.Y.

Roberts, T. R. 1974. Dental polymorphism and systematics in Saccodon, a Neotropical genus of freshwater fishes (Parodontidae, Characoidei). J. Zool. Lond. 173:303-321.

Rubin, C. T., AND L. E. LANYON. 1984. Regulation of bone formation by applied dynamic loads. J. Bone Joint Surg. 66A:397-402.

Sage, R. D., P. V. Loiselle, P. Basasibwaki, AND A. C. WILSON. 1984. Molecular versus morphological change among cichlid fishes of Lake Victoria, pp. 185-197. In A. A. Echelle and I. Kornfield (eds.), Evolution of Fish Species Flocks. Univ. Maine Press, Orono.

Sage, R. D., and R. K. Selander. 1975. Trophic radiation through polymorphism in cichlid fishes. Proc. Nat. Acad. Sci. USA 72:4669-4673.

Savvaitova, K. A. 1973. Ecology and systematics of freshwater chars of the genus Salvelinus (Nilson) from some bodies of water in Kamchatka. J. Ichthyol. 13:58-68.

. 1983. The application of the biological species concept to an evaluation of the systematic position of chars of the genus Salvelinus (Salmonidae). J. Ichthyol. 23:1-12.

SCHLichting, C. D. 1986. The evolution of phenotypic plasticity in plants. Ann. Rev. Ecol. Syst. 17: 667-693. 
Schoener, T. W. 1971. Theory of feeding strategies. Ann. Rev. Ecol. Syst. 2:369-404.

SMITH-GiLl, S. J. 1983. Developmental plasticity: Developmental conversion versus phenotypic modulation. Amer. Zool. 23:47-55.

SoKAl, R. R., AND F. J. RohlF. 1981. Biometry, 2nd Ed. Freeman, San Francisco, CA.

Stearns, S. C. 1983. The evolution of life-history traits in mosquitofish since their introduction to Hawaii in 1905: Rates of evolution, heritabilities, and developmental plasticity. Amer. Zool. 23:6575.

Strauss, R. E. 1984. Allometry and functional feeding morphology in haplochromine cichlids, pp. 217 230. In A. Echelle and I. Kornfield (eds.), Evolution of Fish Species Flocks. Univ. Maine Press, Orono.

SultaN, S. E. 1987. Evolutionary implications of phenotypic plasticity in plants. Evol. Biol. 21:127178.

THORPE, R. S. 1975. Quantitative handling of characters useful in snake systematics with particular preference to intraspecific variation in the ringed snake Natrix natrix. L. Biol. J. Linn. Soc. 7:27-43.

Turner, B. J., AND D. J. Grosse. 1980. Trophic differentiation in Ilyodon, a genus of stream-dwelling goodeid fishes: Speciation versus ecological polymorphism. Evolution 34:259-270.

van OIJEN, M. J. P. 1982. Ecological differentiation among the piscivorous haplochromine cichlids of Lake Victoria (East Africa). Neth. J. Zool. 32:336363.

van Oijen, M. J. P., F. Witte, AND E. L. S. Witte-MaAs. 1981. An introduction to ecological and taxonomic investigations on the haplochromine cichlids from the Mwanza Gulf of Lake Victoria. Neth. J. Zool. 31:149-174.

VIA, S., AND R. LANDE. 1985. Genotype-environment interaction and the evolution of phenotypic plasticity. Evolution 39:505-522.
VRIJenhoek, R. C. 1978. Coexistence of clones in a heterogeneous environment. Science 199:549-552.

VRIJenhoek, R. C., G. Marteinsdottir, AND R. SCHENCK. 1987. Genotypic and phenotypic aspects of niche diversification in fishes, pp. 245-250. In W. J. Matthews and D. C. Heins (eds.), Community and Evolutionary Ecology of North American Stream Fishes. Univ. Oklahoma Press, Norman. In press.

Waddington, C. H. 1942. Canalization of development and the inheritance of acquired characters. Nature 150:563-565.

Waddington, C. H., ANd E. Robertson. 1966. Selection for developmental canalization. Genet. Res. 7:303-312.

WIENS, J. A. 1977. On competition and variable environments. Amer. Sci. 65:590-597.

WilHELM, W. 1984. Interspecific allometric growth differences in the head of three haplochromine species (Pisces, Cichlidae). Neth. J. Zool. 34:622628.

WILKINSON, L. 1986. SYSTAT: The System for Statistics, Version 3.0. Systat, Evanston, IL.

Williamson, P. G. 1981. Palaeontological documentation of speciation in Cenozoic molluscs from Turkana Basin. Nature 293:437-443.

- 1985. Punctuated equilibrium, morphological stasis and the palaeontological documentation of speciation: A reply to Fryer, Greenwood and Peake's critique of the Turkana Basin mollusc sequence. Biol. J. Linn. Soc. 26:307-324.

WITTE, F. 1984. Consistency and functional significance of morphological differences between wildcaught and domestic Haplochromis squamipinnis (Pisces, Cichlidae). Neth. J. Zool. 34:596-612.

Corresponding Editor: R. C. Vrijenhoek 